\title{
A GENERAL PRINCIPLE OF THE DEVELOPMENT PROCESS OF BALANCED SCORECARDS AS AN INSTRUMENT OF CONTROL
}

\author{
Venelin Terziev $^{{ }^{*}}$, Nikolay Nichev ${ }^{2}$, Evgeniy Stoyanov ${ }^{3}$, Marin Georgiev ${ }^{4}$ \\ ${ }^{1}$ Corresponding Member of the Russian Academy of Natural History, Moscow, Russia, Professor, \\ Ph.D., D.Sc. (National Security), D.Sc. (Ec.), University of Rousse, Rousse, Bulgaria; National \\ Military University, Veliko Tarnovo, Bulgaria; University of Telecommunications and Post, Sofia, \\ Bulgaria, terziev@skmat.com \\ ${ }^{2}$ Colonel Associate Professor, Ph.D., National Military University, Veliko Tarnovo, Bulgaria, \\ nicheff@gmail.com \\ ${ }^{3}$ Professor, Ph.D., D.Sc., D.Sc. (Ec.), Agricultural University, Plovdiv, Bulgaria \\ evg_stojanov@abv.bg \\ ${ }^{4}$ National Military University, Veliko Tarnovo, Bulgaria, clementon@abv.bg \\ *Corresponding author
}

\begin{abstract}
The content of the material reveals that the main purpose is to establish the place and role of control principles in creating modern patterns of model managerial thinking such as the Balanced Scorecard. It is for this reason that the process of creating a balanced scorecard and revealing specific control principles in its gradual development is the subject of analysis. Tracking the chronology in the process has made it possible to ascertain in more general terms why the Balanced Scorecard model is gaining more popularity and, more specifically, to see how increasing the perimeter of modular impact predetermines the transformation of the scorecard into a universal methodology for precise and effective, management control.
\end{abstract}

Keywords: Balanced score card (BSC), model, control, principle.

\section{INTRODUCTION}

Every more serious fluctuation in the work of the economic system generates crisis moments. It is then that consultants and representatives of scientific thought begin to look at active patterns and rethink their application based on brain iterations. This is also the case with the model balanced scorecard. After the crisis of confidence in control and auditing from the beginning of the century (Stoyanov E.N., 2013, p. 9) in the world of scientific research and in the consulting practice, the model was viewed from another point of 
view. We can say convincingly that the emphasis on scorecard application has shifted from management to control, and from operations to strategy.

Reasoning on this basis, there has also been a radical change in corporate control activity and the patterns that implement it. In this context, the control activity from an activity having a functional relationship with management aimed at detecting the deviations of the behavior of the managed system and its subsystems and regulating this behavior in accordance with the interests, objectives, plans of the governors, changed into a systemic activity but with predominantly strategic focus.

Based on the detailed analysis of the essential characteristics of the control activity and its basic but also modern forms of expression, it is quite realistic to form an idea of the control principles. Various authors are examined in a different manner, order and composition. This is perfectly acceptable as the control activity is sufficiently diverse and difficult to standardize except general operations (Stoyanov E.N., 2010, p.50). Although each author has applied a different approach to his research, each work has helped to define recurring, general principles of importance for each type of control but also for control as a whole in general.

Similar to the development of the control itself and the related models in the process of their application, they undergo formal and functional development and improvement. Specifically, the balanced scorecard model, developing from a performance management and performance model, is gradually being enriched in a functional way and reveals a great potential for control impact in its application. In this line of thought, it is precisely in the first implemented by Kaplan and Norton implementing technology, considered to be "classical", the presence of certain basic control principles. The detailed analysis by stages demonstrates the following results:

\section{STAGEI-CHARACTERISTICS OF THE INDUSTRY ROLE AND PLACE OF THE COMPANY}

A specific goal at this stage is to form a unified opinion on the specifics and needs of the particular sector, as well as the trends in its improvement and development. Developing a relatively unified view of industry development in the future allows us to create a reliable basis for developing a mission and strategy for the company. A suitable form of realization of the task is the individual interviews, possibly carried out with top managers, informal leaders and other key characters. It has been shown that influence in the formation of strategies is exercised by different models of management thought, engaged in different priority and meaningful weight, such as: SWOT analysis in the mid-1980s, Model of the 5 Competitive Forces in the early 1990s - the resource-oriented analysis of the company, the concept of basic competence at the end of the 90's.

Principles: legality, purposefulness, confidentiality.

\section{STAGE II- DEVELOPMENT AND VALIDATION OF AN ORGANIZATIONAL MISSION}

As far as the Balanced Scorecard (BSC) Model is based on a complex, coordinated presentation of the organization's mission, a consensus on this point is needed at the $\mathrm{I}^{-\mathrm{st}}$ stage. The content at this stage is committed to the final consolidation of the mission of the organization under consideration, the attitude towards the strategic model of the BSC and the alignment of the views on this issue. At this stage, the answer to specific questions is solving the problems of this stage, namely: formulating a mission; providing an incentive to develop the strategy; establishing a logical link between mission and personal goals and setting up a mission geared to the sustainable development of the particular organization. Based on the background information collected in the first stage and an analysis of certain factors related to the organization's activities, a mission proposal is formed. It is essential to mention some of them, such as: the state of the business environment, shareholders' demands, the financial situation, the basic competence of the organization and the level of technological development.

Principles: system, prognostics.

\section{STAGE III- IDENTIFYING KEY ASPECTS OF THE ORGANIZATIONAL ACTIVITY}

This stage is particularly important due to the fact that after the formulation of a corporate strategy, mission, vision and an established management model such as BCS, then comes the analysis of the activity and the selection of individual aspects of this activity. The baseline model of Kaplan and Norton has four key aspects of activity. Along with this, there are formulated those to be included in the strategic scorecard. In identifying the key aspects it is difficult to register interdependencies between them. „In this process of determining a leading factor is the logic of the development of the particular business". (Neely A., 1998, p. 117). As far as 
possible, every aspect of the development of a particular business should be tied to a specific financial measure. As a result of the seminar at this stage, we reach an analysis of the overall activity of the organization, reflected both in plan analysis and in terms of formulation of aspects, and at the same time levers and factors influencing the mission statement.

Principles: prevention and adequacy.

\section{STAGEIV-DETAILS OF THE ORGANIZATIONAL MISSION}

Formulating strategic goals.

Building on the formulated key aspects of the activity and their links to the mission at this stage, the participants in the next seminar will introduce a list of rules and procedures that will allow the mission to be carried out effectively. Each key activity implies a range of issues that cause action to be taken to resolve them. As a result of this seminar, the participants receive a description of each key aspect, indicating the main variables in the functional strategy and their priorities. On the basis of this whole process, in the development of every aspect of the company's activities, strategic goals are formed - a necessary result and a prerequisite for further development. The essence at this stage is to transform the aggregated corporate mission to a concretely practicable level, providing a delicate balance between long-term and short-term goals. This is one of two important trends for the practical improvement of business models. The other is an increasingly comprehensive formulation of a strategy, and its implementation always faces the problem of winning and retaining a significant competitive advantage from the long-standing balancing scorecard experience. Analyses prove that the method of linking a strategy with views on the development is usually a guarantee of success.

Principles: relevance and independence.

\section{STAGE V- IDENTIFYING KEY SUCCESS FACTORS}

At this stage, a transition is made from the general definition and description of the strategy discussed up to defining the means of implementation and the most significant key factors, i.e., which factors have a decisive role in achieving success and ranking them in a logical order of priority. The logic of this priority is linked, on the one hand, to their role in the implementation of strategic goals and, on the other hand, to their impact on specific financial results, and here is the actual expression of the Value Maximization Theory. Before proceeding with the development of key indicators, it is desirable to shift the key success factors in the strategic scorecard into vertical and horizontal order, otherwise said, this helps to convince the participants that the model is based on internally consistent and interrelated information (Stoyanov E. N., 2005, p. 79). The location of horizontal factors is not very complex, but rather has a registration character. Reflection along the vertical, however, is related to the specific dynamics of a certain factor and its assignment to separate semantic and logical blocks of interconnections. These forms of organization are linked to a vertical alignment of priorities.

Principles: adequacy, purposefulness.

\section{STAGE VI- DEVELOPING A SYSTEM OF INDICATORS}

\section{Coordination of short and long-term goals}

At this stage of development, an adequate system of key performance indicators is developed to be applied in the next stages. At this stage, it is necessary to make a precise choice exactly because here is quite likely that the information distortion will distort the specific strategic goal. At the end of the stage, the indicators that most adequately reflect the current situation and allow to observe the dynamics of development and the smallest deviations are finally selected and arranged in perspective. The complexity of the stage stems from the recording of cause-and-effect links and the reconciliation of the selected indicators between them. It is important to select indicators that reconcile the interdependence between short-term goals and long-term alternatives. This stage is considered as a whole action and a logical result, prepared by a number of prerequisites. Not a few specialists believe that perhaps its structure is more appropriate to be considered as two separate sub-stages. In the first, an analysis is carried out and a list of indicators is created according to meaning and value (Stoyanov E.N., 2007, p. 133). For adequate objectivity, according to the needs of the organizations in the last years, the consultants use for analysis and location of each individual indicator a Success rate, formed on the basis of a ratio of complexity to degree of performance. As a result of the second sub-stage, a set of indicators is finally set up after checking for lack of internal contradictions.

Principles: independence, objectivity, expedience. 


\section{STAGE VII-CREATING A CORPORATE STRATEGY SCORECARD}

This is the stage of formulating the strategic scorecard at the corporate level. Here, a particularly important point is to discuss and validate its content, above all to synchronize intangible assets with strategy. The objective discussion of the scorecard is a highly dynamic debate because the scorecard itself can and should be seen as a constantly evolving process. A very important moment in a seminar is that each participant in the seminar will define his attitude towards the project and outline the way of his participation. An important milestone in the workshop is making comments and making proposals for modeling strategic scorecards for different organizational levels.

Principles: legality, purposefulness.

\section{STAGE VIII- STRUCTURING SCORECARDS FOR INDIVIDUAL SUBDIVISIONS}

An essential prerequisite for the development of this stage is the form and content of the corporate strategic scorecard. Depending on the size of the organization under consideration and its structural specificity, the order of strategic scorecard development for the individual structural units is defined, in adapting the corporate scorecard to their specifics. For the successful implementation of the decomposition of the corporate scorecard and the development of strategic scorecard samples for individual units, the process of organizational optimization has to be finalized. When implementing strategic scorecards for individual units, then when they are bound to a complete production cycle, it is a good idea to set up a common scorecard with separate goals. The complexity of the decomposition process can be judged by the problems arising at each level and unit of the structure. An important moment in summarizing the results of the submitted proposals in the seminar is the presence of middle echelon managers involved in the realization of the project at lower hierarchical levels.

Principles: system and prognostics.

\section{STAGE IX- FORMULATING SPECIFIC GOALS}

Valuing specific intentions and strategic goals for each indicator, both at corporate level and at a lower level, is an essential process that results in the formation and set-up of planning value and consensus on the correctness of the organization's mission and strategy. In the same time it is also duly laid control over their implementation for a future period coinciding with the planning period. This stage is committed to the formulation of specific targets for each indicator included in the strategic scorecard. To this end, it is necessary to establish a predictive meaning with a fixed value, a numerical expression of the stated objectives. In connection with the implementation of the task, it is good for each organization to record shortterm and long-term goals, creating conditions for corrections.

Principles: purposefulness and expediency.

\section{STAGE X- DEVELOPING A PLAN OF EVENTS}

The introduction of target planning values for each indicator is an essential prerequisite for the development of this stage. The implementation of this task is related to a number of events from the individual to the corporate level, while making proposals at a seminar for initiatives related to specific strategic goals and their future implementation. At the end of the stage, lists of groups of proposals for individual aspects related to the issues and events are submitted to the seminar. The strategic role of intangible assets cannot be implemented on its own. To use them effectively, the organization needs a unified program, it needs developing a plan of events. In order to finalize the process of developing a strategic scorecard, it is necessary to fix specific actions for their implementation in the overall plan involved with the integration of strategy and mission. This plan has to be considered so that the specific actions, implementation deadlines and financial results are logically linked to a single corporate strategy. In practice, it turned out that instead of constant monitoring of specific key indicators, this action plan is a more effective control tool (Stoyanov E.N., 2009, p. 123-125).

Principles: system, prognostics.

\section{STAGEXI- INTRODUCING SCORECARDS}

Stage of expected result, where everything so far is a prerequisite for a good result. The plan of events and the strategy scorecard implementation algorithm is desirable to include initiatives and procedures for control, which is why the management based on them will become part of the organization's day-to-day activities. An essential point in the implementation of this project is the possibility to apply at all levels and for all 
subdivisions strategic scorecards of the type BSC. This is a desirable stage in designing balanced scorecards, because in a complex structure the implementation of a strategic project involves a number of problems in creating an array of reliable and timely information about creating an appropriate plan of specific events, based on proven cumulative effect of shared strategy.

Principles: confidentiality and independence.

\section{CONCLUSION}

This expose provides evidence to draw two general conclusions:

First.The development and improvement of the Balanced Scorecard model is the principle of the control start, and this predetermines the model transformation and extension of the functional application. Social and corporate needs justifiably imply the development of the concept of management control and consolidate the potential of balanced scorecards to the needs of society for adequate, timely and effective control far beyond the limits of traditionally known and established forms of control.

Second. The presence of almost all control principles without the principle of economy can be interpreted in two ways. On the one hand, the value of the project balanced scorecard has a price that is not at all low. But on the other hand, the scorecard is not a momentary state, but a process that evolves and improves. It is with this logic that the expectations of the users are focused on that the time, benefits and the effect of the introduction of the scorecard samples should not only redeem the implementation costs but also form a new structure of the modern organization where the intangible assets generate ever greater contributions.

\section{REFERENCE LIST}

Stoyanov E.N., (2013) Audit - sources and institutionality, Burgas, Flat.

Stoyanov E.N., (2010) FinancialControl, Burgas, LibraScorpio, p.50.

Neely A., (1998) Measuring Business Performance, p.117.

Stoyanov E. N., (2005) OneSuccessfulldeainStrategicControl, Burgas, Anthey-TN, p.79.

Stoyanov E.N., (2007) Methodological Aspects of the Balanced Scorecard as a Tool for Strategic Control, (dissertation) Sofia, UNWE, p.133.

Stoyanov E.N., (2009) Systems of Management Control, Burgas, Libra Scorpion, p.123-125. 